Document downloaded from:

http://hdl.handle.net/10251/54629

This paper must be cited as:

Rubio Marqués, P.; Hernández Garrido, JC.; Leyva Perez, A.; Corma Canós, A. (2014). One pot synthesis of cyclohexanone oxime from nitrobenzene using a bifunctional catalyst. Chemical Communications. 50(14):1645-1647. doi:10.1039/c3cc47693f.

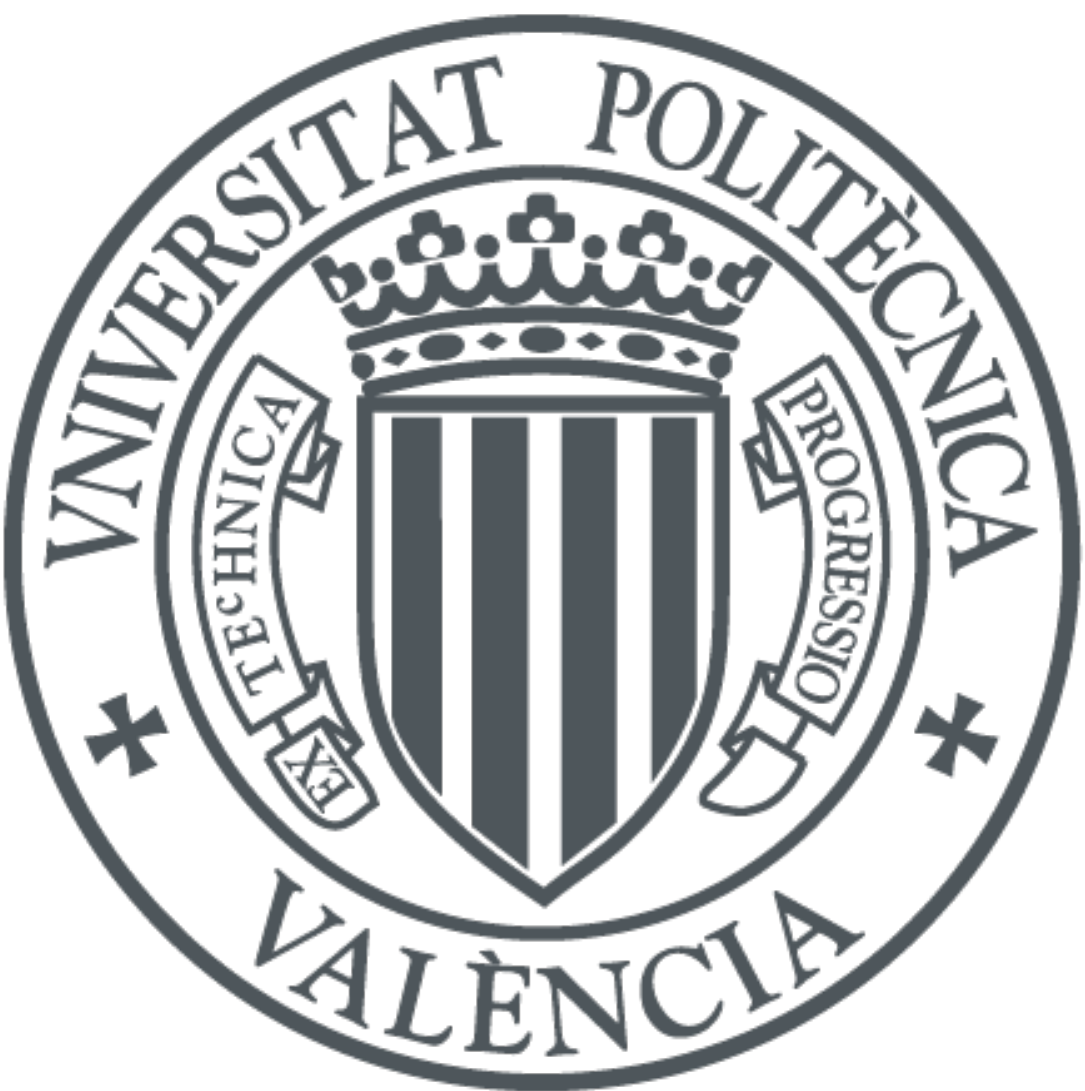

The final publication is available at

Copyright Royal Society of Chemistry

Additional Information 


\title{
COMMUNICATION
}

Cite this: DOI: $10.1039 / \times 0 \times x 00000 x$

\section{One pot synthesis of cyclohexanone oxime from nitrobenzene with a bifunctional catalyst}

\author{
Paula Rubio-Marqués, ${ }^{a}$ Juan Carlos Hernández-Garrido, ${ }^{b}$ Antonio Leyva-Pérez, ${ }^{* a}$ and \\ Avelino Corma*a
}

Received 00th January 2012,

Accepted 00th January 2012

DOI: $10.1039 / \times 0 \times x 00000 x$

www.rsc.org/

Cyclohexanone oxime is formed from nitrobenzene with $97 \%$ yield in a one-pot reaction catalysed by palladium and gold nanoparticles on carbon. The reaction is carried out under hydrogen at $60^{\circ} \mathrm{C}$ and the overall transformation involves a multi-step catalysed mechanism from which intermediates and catalytic active species have been identified.

Cyclohexanone oxime is the key intermediate in the production of nylon 6 fibers and resins, and the worldwide market is one of the largest among chemical products. ${ }^{1}$ Manufacturing is typically carried out in a three-step procedure: a) synthesis of cyclohexane by metalcatalysed hydrogenation of benzene ${ }^{2}$ b) synthesis of cyclohexanone by oxidation of cyclohexane at low conversions per pass $(<8 \%)^{3-5}$ or by hydrogenation of phenol; ${ }^{6-9}$ and c) formation of cyclohexanone oxime from cyclohexanone and external hydroxylamine or hydroxylamine formed in situ with aqueous $\mathrm{NH}_{3}$ and $\mathrm{H}_{2} \mathrm{O}_{2}$.

Modern chemical industry demands the intensification of chemical processes in order to save chemicals, energy and waste-treatments ${ }^{13-}$ 15 and, to our knowledge, only one example has applied the concept of one-pot reaction for some steps during the synthesis of cyclohexanone oxime, ${ }^{16}$ from phenol to $\varepsilon$-caprolactam.

Figure 1 shows the long-sought hydrogenation of nitrobenzene to cyclohexanone oxime, a paradigmatic example of process intensification since nitrobenzene is a multi-ton primary product of benzene with all the atoms needed to form the cyclohexanone oxime structure. Then, it will be much interesting from a fundamental, as well as from an applied point of view, to find a catalytic process able to directly convert nitrobenzene into cyclohexanone oxime.

Here we show that cyclohexanone oxime is formed in high yields from nitrobenzene in a one-pot reaction using palladium and gold nanoparticles supported on carbon as a catalyst under hydrogen atmosphere. An in-depth study of the mechanism will show the role of both metal catalysts in each step of the reaction sequence.

- One-pot hydrogenation of nitrobenzene to cyclohexanone oxime with a $\mathrm{AuPd} / \mathrm{C}$ catalyst.

Figure 1 shows that when nitrobenzene 1 was reacted with hydrogen in the presence of catalytic amounts of AuPd/C (5 mol\%) and hydroxylamine hydrochloride, cyclohexanone oxime $\mathbf{2}$ was obtained in a remarkable $67 \%$ yield.

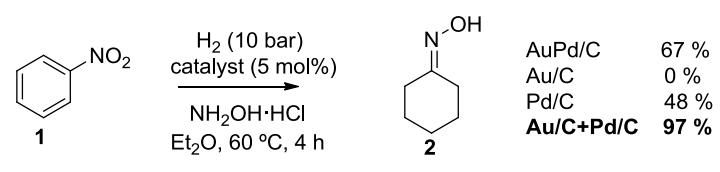

Figure 1. Hydrogenation of nitrobenzene to cyclohexanone oxime under static pressure catalysed by $\mathrm{Au}$ and/or $\mathrm{Pd} / \mathrm{C}$ catalysts. The yield with $\mathrm{Au} / \mathrm{C}+\mathrm{Pd} / \mathrm{C}$ is reproduced with semi-continuous dynamic pressure (see Suppo. Info. for details).

If $\mathrm{Au} / \mathrm{C}$ is used alone under the same catalytic loading, cyclohexanone oxime 2 is not obtained. On the other hand, if $\mathrm{Pd} / \mathrm{C}$ is used alone it is possible to obtain the oxime but the yield is below $50 \%$. Other metals such as ruthenium, iron and rhodium were also ineffective to catalyse the formation of cyclohexanone oxime $\mathbf{2}$ (Table S1, Suppo. Info.). The AuPd/C catalyst was characterized by Electron Dispersive X-Ray spectroscopy (EDX) coupled to HighResolution Transmission Electron Microscopy (HR-TEM, Figure $\mathrm{S} 1 \mathrm{~A})$. It can be observed there that the catalyst is composed by welldispersed small $(<3 \mathrm{~nm})$ palladium nanoparticles, gold being separated and grouped into $20 \mathrm{~nm}$ particles. Mapping of $\mathrm{AuPd} / \mathrm{C}$ showed no clear interaction between both metals (Figures S1B-C) and, since the nanoparticles of each metal were independent in the $\mathrm{AuPd} / \mathrm{C}$ catalyst, we compared the catalytic activity of a physical mixture of $\mathrm{Au} / \mathrm{C}$ and $\mathrm{Pd} / \mathrm{C}$, i.e., supported gold and supported palladium on separated carbon particles, and the yield of cyclohexanone oxime 2 increased to $97 \%$ (see Figure 1, the reaction can also be carried out at the gram scale with high yields of isolated oxime). TEM images of the reference catalyst, with palladium and gold placed in different particles, showed a particle size similar to that of $\mathrm{AuPd} / \mathrm{C}$ for each metal $(>5 \mathrm{~nm}$ for gold and $<3 \mathrm{~nm}$ for palladium in $\mathrm{Au} / \mathrm{C}$ and $\mathrm{Pd} / \mathrm{C}$ respectively, Figures $\mathrm{S} 2-3$ ). These results reflect that $\mathrm{Au}$ and $\mathrm{Pd}$ are involved in different steps of the catalytic cycle and the absence of any of both metals somehow hampers the formation of cyclohexanone oxime $\mathbf{2}$. If desired, the amount of noble metals can be decreased below 1 mol\% provided longer reaction times are set (Table S2).

At this point, and in order to find the reaction network and the role of each metal component, the single metal $\mathrm{Au} / \mathrm{C}$ and $\mathrm{Pd} / \mathrm{C}$ catalysts 
were studied independently in the different reaction steps. First, when nitrobenzene 1 was reacted in the presence of $\mathrm{Au} / \mathrm{C}$ but in the absence of hydroxylamine hydrochloride, the only product obtained was aniline 3 (Figure 2). However, the same reaction but in the presence of $\mathrm{Pd} / \mathrm{C}$ gave, surprisingly, cyclohexhylaniline 4 and dicyclohexylamine $\mathbf{5}$ as the main products. It seems then plausible that $\mathrm{Au} / \mathrm{C}$ is unable to reduce nitrobenzene $\mathbf{1}$ further than aniline $\mathbf{3}$, while the $\mathrm{Pd} / \mathrm{C}$-catalysed formation of the secondary amines $\mathbf{4}$ and $\mathbf{5}$ is in some way connected with the synthesis of cyclohexanone oxime 2 .

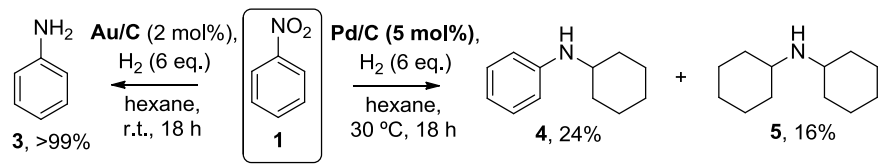

Figure 2. Role of $\mathrm{Au} / \mathrm{C}$ and $\mathrm{Pd} / \mathrm{C}$ in the hydrogenation of nitrobenzene $\mathbf{1 .}$

Figure 3 shows kinetics for the hydrogenation of nitrobenzene 1 with the $\mathrm{Pd} / \mathrm{C}$ catalyst, in where each point corresponds to an independent batch reaction. Aniline $\mathbf{3}$ is formed as a primary and unstable product that, by partial hydrogenation, gives cyclohexylaniline 4 as a secondary product that, by further hydrogenation, produces dicyclohexylamine $\mathbf{5}$ as a tertiary product. No intermediate diazo products were detected. ${ }^{17-19}$ The reaction sequence was confirmed by reacting cyclohexylaniline 4 at $60{ }^{\circ} \mathrm{C}$ in the presence of $\mathrm{Pd} / \mathrm{C}$. In that case, dicyclohexylamine $\mathbf{5}$ was obtained with very high selectivity, as a primary product.

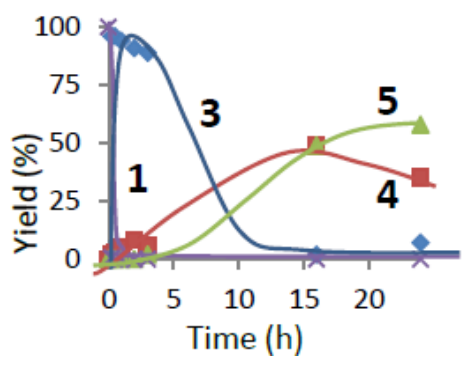

Figure 3. Plot-time
yield for the
hydrogenation of
nitrobenzene 1 with the
$\mathrm{Pd} / \mathrm{C}$ catalyst at $60{ }^{\circ} \mathrm{C}$.
Each kinetic point
belongs to an
independent reaction.

It is interesting to notice that cyclohexanamine $\mathbf{6}$ was not observed among the reaction products. Since the hydrogenation of the primary product aniline $\mathbf{3}$ to cyclohexanamine $\mathbf{6}$ is very plausible, the latter must be rapidly consumed during the process, and a possible way would be the corresponding condensation with $\mathbf{3}$ to form cyclohexylaniline 4. To check this hypothesis, aniline $\mathbf{3}$ and cyclohexanamine $\mathbf{6}$ were reacted under the above reaction conditions in the presence of $\mathrm{Pd} / \mathrm{C}$ and a combined $55 \%$ yield of the coupled products $\mathbf{4}$ and $\mathbf{5}$ was observed. This result strongly suggests that $\mathrm{Pd} / \mathrm{C}$ catalyses the formation of $\mathbf{4}$ and $\mathbf{5}$ from nitrobenzene $\mathbf{1}$ in the presence of $\mathrm{H}_{2}$ by in-situ condensation of aniline $\mathbf{3}$ and cyclohexanamine $\mathbf{6}$. We then postulate a hydrogen-borrowing mechanism to explain the formation of cyclohexylaniline $\mathbf{4}$, as shown in Figure 4. Thus, dehydrogenation of $\mathbf{6}$ would give cyclohexanimine $\mathbf{7}$ that couples with remaining aniline $\mathbf{3}$ to give cyclohexylaniline 4, after ammonia release. The hydrogen borrowing mechanism is consistent with the kinetic experiments in Figure 3 since aniline $\mathbf{3}$ is smoothly consumed while the coupled products are formed, and production of cyclohexylaniline $\mathbf{4}$ stops when no aniline 3 remains in the reaction media.

Figure 5A shows that, if $\mathrm{Au} / \mathrm{C}$ is added to the reaction in the presence of $\mathrm{Pd} / \mathrm{C}$, the formation of secondary amines is nearly suppressed and cyclohexanone $\mathbf{9}$, the necessary precursor for cyclohexanone oxime $\mathbf{2}$, is formed, together with small amounts of cyclohexylaniline 4 .

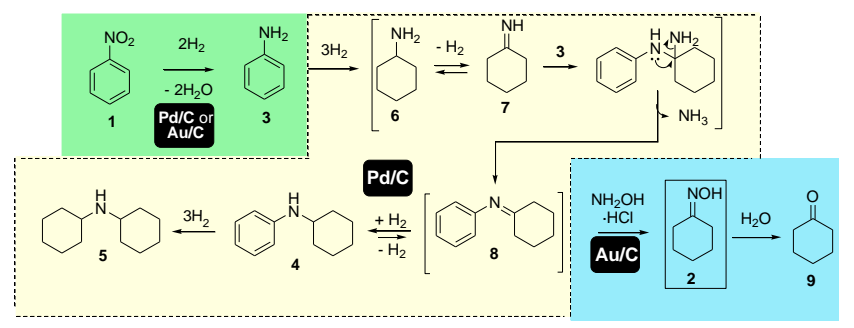

Figure 4. Proposed mechanism for the $\mathrm{Au} / \mathrm{C}$ and $\mathrm{Pd} / \mathrm{C}$-catalysed hydrogenation of nitrobenzene $\mathbf{1}$ to cyclohexanone oxime $\mathbf{2}$, cyclohexylaniline $\mathbf{4}$ and dicyclohexylamine $\mathbf{5}$.

Since dicyclohexylamine $\mathbf{5}$ is not detected when $\mathrm{Au} / \mathrm{C}$ is added and cyclohexanone oxime $\mathbf{2}$ is formed, it seems reasonable to associate the role of the gold catalyst to a reaction with cyclohexylaniline 4 . However, cyclohexanone $\mathbf{9}$ was not formed if $\mathbf{4}$ was reacted in the presence of the $\mathrm{Au} / \mathrm{C}$ catalyst, even if $\mathrm{Pd} / \mathrm{C}$ is present (Figure $5 \mathrm{~B}$ ). Following the hydrogen-borrowing mechanism in Figure 4, it sounds plausible that cyclohexylaniline $\mathbf{4}$ could be in equilibrium with the corresponding imine $\mathbf{8}$ and, since the latter is reluctant to further amine condensation, ${ }^{20-22}$ there is an opportunity for further hydrolysis to give cyclohexanone 9 . To check that, the intermediate $\mathrm{N}$-cyclohexylideneaniline $\mathbf{8}$ was synthesized $^{23}$ and tested under reaction conditions with the $\mathrm{Au} / \mathrm{C}$ catalyst (Figure 5C). The result shows that cyclohexanone $\mathbf{9}$ was obtained in significant yields. In contrast, $\mathrm{Pd} / \mathrm{C}$ catalyses the hydrolysis in a much lesser extent, after correction with the blank experiment. These results strongly suggest that gold catalyses the hydrolysis of $\mathrm{N}$-cyclohexylideneaniline $\mathbf{8}$ formed from 4 . The possible hydrolysis of cyclohexanimine 7 must not be excluded.

The activation of imine $\mathbf{8}$ requires an acid resistant to hydrogenation. However, many Lewis metal cations, able to catalyse the hydrolysis of $\mathbf{8}$, will be rapidly reduced under the strong hydrogenating conditions of the reaction. Brönsted acids are of course reluctant to hydrogenation, but independent experiments with acetic, sulfuric and $p$-toluenesulfonic acid, besides $\mathrm{HCl}$, showed low amounts of cyclohexanone 9 (Table S3). In contrast, it appears that gold nanoparticles possess certain Lewis acidity even under hydrogenating conditions and, for instance, it has been reported that gold-supported nanoparticles are able to activate imines towards hydroalkynylations. ${ }^{24}$ However, the formation of the imine on supported-Pd sites makes difficult that the Lewis activation of the imine occurs in Au-supported sites since both sites are separated, as previously shown. Thus, it was studied if one of the catalysts for the oxime formation, palladium or gold, may have free movement in the reaction or, in other words, be soluble. For that, we carried out the oxime formation from $\mathbf{8}$ with catalytic amounts of palladium(II) chloride, gold(I) chloride, soluble palladium nanoparticles, and gold nanoparticles (see Figure 5C) but none of them improved the formation of oxime from $\mathbf{8} .^{25-27}$ However, the reaction occurred in good extent when we used a sample of $\mathrm{Au} / \mathrm{CeO}_{2}$ containing leachable sub-nanometric gold clusters. ${ }^{26}$ Soluble sub-nanometric gold clusters have recently show extremely high catalytic activities for hydration reactions ${ }^{28}$ and since gold nanoparticles were not active, the catalytic activity of $\mathrm{Au} / \mathrm{CeO}_{2}$ suggests that gold clusters might be involved in the hydrolysis of $\mathbf{8}$ to cyclohexanone 9. X-ray Photoelectron Spectroscopy (XPS) of the Au/C catalyst confirmed the presence of $\sim 10 \%$ cationic gold species on the solid, as occurs in $\mathrm{Au} / \mathrm{CeO}_{2}$ (Figure S4).To confirm the presence of gold clusters in solution during reaction, fluorescence measurements of the reaction 
mixture after filtration of the $\mathrm{Au} / \mathrm{C}$ and $\mathrm{Pd} / \mathrm{C}$ solids were carried out. According to the jellium theory, these clusters should present clear fluorescence bands in the visible region and, in addition, the corresponding wavelength emission would give an estimation of the cluster size. ${ }^{28}$ Since it is known that the other chromophores in the reaction medium such as nitrobenzene, protonated anilines and cyclohexanone oxime does not have fluorescence bands, which was confirmed by blank experiments, we must accept that the emission bands shown in Figure 6A belong to small gold clusters within a wavelength range expected for 3 atoms. Ultraviolet-visible spectroscopy (UV-Vis) showed the complete absence of the plasmon band and thus of gold nanoparticles in solution ( $550 \mathrm{~nm}$, Figure 6B).
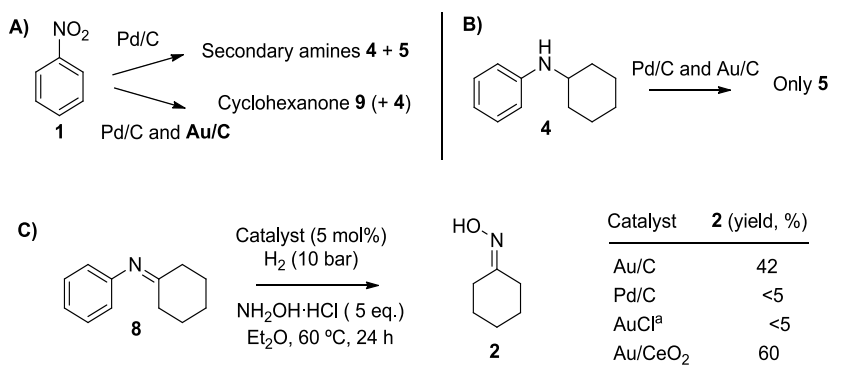

Figure 5. A) Synthetic switch to cyclohexanone 9 by Au/C. B) Failed formation of 9 from cyclohexylaniline 4. C) Hydrolysis of $N$ cyclohexylideneaniline $\mathbf{8}$ under hydrogenating conditions with different catalysts. Yields are corrected after blank experiments. ${ }^{\text {a }}$ Similar results for $\mathrm{PdCl}_{2}$, soluble palladium nanoparticles and gold nanoparticles.

Dynamic Light Scattering (DLS) combined with Zeta-potential measurements (Figure S5) revealed that these sub-nanometric particles present in solution are positively-charged. From all the above results one may suggest that sub-nanometric gold clusters leached into solution are responsible for the last catalysed step of the transformation of nitrobenzene $\mathbf{1}$ to cyclohexanone oxime $\mathbf{2}$, namely the hydrolysis of imine $\mathbf{8}$.

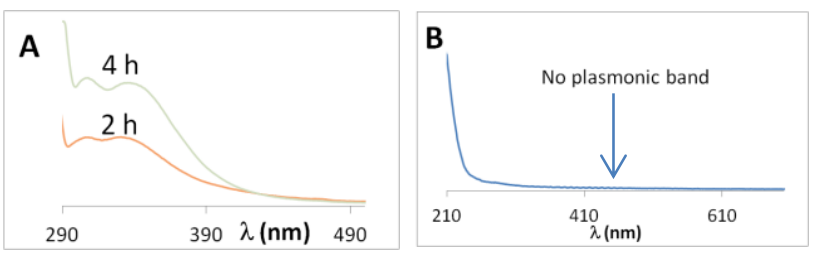

Figure 6. A) Fluorescence measurements of the reaction mixture for the formation of cyclohexanone oxime 2 under $\mathrm{Au} / \mathrm{C}$ and $\mathrm{Pd} / \mathrm{C}$ catalysed conditions. B) Corresponding UV-vis spectrum at $2 \mathrm{~h}$.

\section{Conclusions}

In summary, we have described here the synthesis of cyclohexanone oxime from nitrobenzene with $\mathrm{Pd}$ and $\mathrm{Au}$ on carbon in a multi-step cascade reaction that involves: 1) Hydrogenation of $\mathbf{1}$ to aniline $3 ; 2$ ) further hydrogenation of $\mathbf{3}$ to cyclohexanamine $\mathbf{6}$; 3) coupling of $\mathbf{3}$ and $\mathbf{6}$ by hydrogenborrowing mechanism to form amine 4 ; 4) formation and hydrolysis of the imine $\mathbf{8}$ to generate cyclohexanone $\mathbf{9}$ and aniline $\mathbf{3}$ that is recycled for the coupling; and 5) formation of oxime 2 . The cascade reaction can potentially be extended since the production of hydroxylamine hydrochloride is based on the $\mathrm{Pd} / \mathrm{C}$-catalysed hydrogenation of ammonium nitrate and the latter is produced from nitric acid and ammonia (Figure S6), all these chemicals being used in the process reported here.

\section{Notes and references}

${ }^{a}$ Instituto de Tecnología Química, Universidad Politécnica de ValenciaConsejo Superior de Investigaciones Científicas (UPV-CSIC.)

Avda. De los Naranjos S/N, Valencia, Spain. Fax: 3496387 7809; Tel: +34963877800

E-mail: anleyva@itq.upv.es, acorma@itq.upv.es

${ }^{b}$ Departamento de Ciencia de los Materiales e Ingeniería Metalúrgica y Química Inorgánica, Facultad de Ciencias, Universidad de Cádiz, Campus Río San Pedro S/N, Puerto Real-Cádiz, Spain

Electronic Supplementary Information (ESI) available: Experimental procedures, additional Figures and Tables. See DOI: 10.1039/c000000x/

1. H. Ichihashi and H. Sato, Appl. Catal. A Gen., 2001, 221, 359-366.

2. J. M. Calderon-Moreno, V. G. Pol and M. Popa, Eur. J. In. Chem., 2011, 2011, 2856-2862.

3. R. Mokaya and M. Poliakoff, Nature, 2005, 437, 1243-1244.

4. S. S. Stahl, Science, 2005, 309, 1824-1826.

5. J. M. Thomas, R. Raja, G. Sankar and R. G. Bell, Nature, 1999, 398, 227-230.

6. J. Matos and A. Corma, App. Catal. A Gen., 2011, 404, 103-112.

7. H. Liu, T. Jiang, B. Han, S. Liang and Y. Zhou, Science, 2009, 326, $1250-1252$.

8. L. M. Sikhwivhilu, N. J. Coville, D. Naresh, K. V. R. Chary and V. Vishwanathan, App. Catal. A Gen., 2007, 324, 52-61.

9. C. V. Rode, U. D. Joshi, O. Sato and M. Shirai, Chem. Commun., 2003, 0, 1960-1961.

10. K. Suzuki, T. Watanabe and S.-I. Murahashi, Angew. Chem. Int. Ed., 2008, 47, 2079-2081.

11. J. M. Thomas and R. Raja, Proc. Nat. Acad. Sc. U.S.A., 2005, 102, 13732-13736.

12. K. Sato, M. Aoki and R. Noyori, Science, 1998, 281, 1646-1647.

13. M. J. Climent, A. Corma and S. Iborra, Chem. Rev., 2010, 111, $1072-$ 1133.

14. K. C. Nicolaou, D. J. Edmonds and P. G. Bulger, Angew. Chem. Int. $E d ., 2006,45,7134-7186$.

15. P. J. Parsons, C. S. Penkett and A. J. Shell, Chem. Rev., 1996, 96, 195-206.

16. J. Y. Shin, D. J. Jung and S.-g. Lee, ACS Cat., 2013, 525-528.

17. A. Grirrane, A. Corma and H. García, Science, 2008, 322, 16611664.

18. A. Corma, P. Concepción and P. Serna, Angew. Chem. Int. Ed., 2007, 46, 7266-7269.

19. A. Corma and P. Serna, Science, 2006, 313, 332-334.

20. G. Guillena, D. J. Ramón and M. Yus, Chem. Rev., 2009, 110, 16111641.

21. D. Hollmann, S. Bahn, A. Tillack and M. Beller, Chem. Commun., 2008, 3199-3201.

22. D. Hollmann, S. Bähn, A. Tillack and M. Beller, Angew. Chem. Int. Ed., 2007, 46, 8291-8294.

23. J. Barluenga, A. n. Jiménez-Aquino, F. Aznar and C. Valdés, J. Am. Chem. Soc., 2009, 131, 4031-4041.

24. X. Zhang and A. Corma, Angew. Chem. Int. Ed., 2008, 120, 44304433.

25. K.-i. Shimizu, T. Yamamoto, Y. Tai and A. Satsuma, J. Mol. Catal.s A Chem., 2011, 345, 54-59.

26. C. Jeyabharathi, S. Senthil Kumar, G. V. M. Kiruthika and K. L. N. Phani, Angew. Chem. Int. Ed., 2010, 49, 2925-2928.

27. A. K. Sinha, M. Basu, S. Sarkar, M. Pradhan and T. Pal, J. Coll.Interf. Sci., 2013, 398, 13-21.

28. J. Oliver-Meseguer, J. R. Cabrero-Antonino, I. Domínguez, A. Leyva-Pérez and A. Corma, Science, 2012, 338, 1452-1455. 